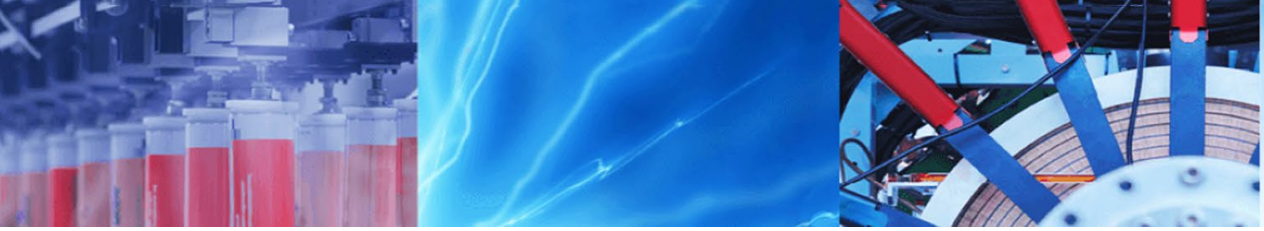

Research Article

\title{
Optical absorption spectra of germinated seedlings from seeds exposed to vehicle polluting gases
}

\author{
J. E. Valencia-Hernandez ${ }^{1}$ (D) . C. Hernandez-Aguilar ${ }^{1}$ (D) $\cdot$ A. Dominguez-Pacheco ${ }^{1}$ (D) $\cdot$ A. Cruz-Orea ${ }^{2}$ (D)
}

Received: 15 November 2019 / Accepted: 4 March 2020 / Published online: 11 March 2020

(c) Springer Nature Switzerland AG 2020

\begin{abstract}
High pollution rates in large cities have had a negative impact on human, animal and plant health. In the case of plants, several techniques have been used to analyze the physical and physiological parameters of their seedlings and seed germination process, under different environmental conditions. This study proposed the evaluation of seedlings from corn, lentils and bean seeds, exposed to polluting gases $\left(\mathrm{CO}, \mathrm{CO}_{2}\right)$ through a container system of a vehicle engine, during different times (0, 20, 40,60 and $80 \mathrm{~min})$. The seeds, after the exposition to the pollutant gases, were planted, and the optical absorption spectra of each seedling were obtained by photoacoustic spectroscopy. The absorption spectra were obtained in a wavelength range from 250 to $750 \mathrm{~nm}$. The obtained spectra demonstrated significant statistical differences in the wavelength range from 290 to $300 \mathrm{~nm}$ (corresponding to optical absorption mainly by flavonoids) and also from 650 to $680 \mathrm{~nm}$ (corresponding to optical absorption of chlorophylls). In addition, changes in physiological parameters, during the seed germination process, were evaluated.
\end{abstract}

Keywords Photoacoustic spectroscopy · Polluting gases · Air pollution · Seeds · Germination

\section{Introduction}

Environmental air pollution is one of the world's problems that has grown in recent years, causing approximately 7 Mio. deaths worldwide. According to WHO reports in 2018; 9 out of 10 people breathe air that contains high levels of contaminants [1]. Among the main sources of pollutants in the air are those produced by mankind due to the combustion of fuels in industry, heating, motor vehicles, etc., Fuels and oils are essential for the operation of motor vehicles; using both contributes to emissions of pollutants [2]. Many of these fuels and oils produce high emissions of nitrogen oxide (NO), volatile organic compounds (VOCs), ozone $\left(\mathrm{O}_{3}\right)$, fine particles (PM10 and PM2.5), carbon dioxide $\left(\mathrm{CO}_{2}\right)$ and carbon monoxide $(\mathrm{CO})[3,4]$. Internal combustion engines use fuels that contain carbon, for example gasoline, kerosene, oil, propane and coal [5]; in these engines, an incomplete combustion process produces $\mathrm{CO}$ at concentrations varying from 300 to 1200 and 1500 to $4000 \mathrm{ppm}$ for diesel and gasoline engines, respectively; these high $\mathrm{CO}$ concentrations are due to the low presence of oxygen in the combustion of fossil fuels. $\mathrm{CO}$ is considered as one of the most important pollutants in the air [6-9].

The effects of polluting gases, emitted by thousands of vehicles every day in large cities, have been investigated by measuring the impact that they generate on animals $[10]$ and vegetation $[2,11]$. The literature reports the effects produced by the emission of motor vehicles on physiological behavior in plants, in the short and long terms, of different varieties of species and functional types, such as trees, shrubs and plants, exposed to $\mathrm{CO}$ and $\mathrm{CO}_{2}$

\footnotetext{
$\triangle$ A. Dominguez-Pacheco, fartur@hotmail.com | ${ }^{1}$ Posgrado en Ingeniería de Sistemas, Instituto Politécnico Nacional, SEPI-ESIME-Zac., Av. Instituto Politécnico Nacional, s/n, Alcaldía Gustavo A. Madero, Col. Lindavista C.P., 07730 City of Mexico, Mexico. ${ }^{2}$ Departamento de Física, CINVESTAV-IPN, A. P. 14-740, 07360 City of Mexico, Mexico.
} 
gas emissions produced by motor vehicle traffic [3, 11-13]. Some of these studies were conducted by evaluating, in an uncontrolled environment, seeds and trees growing near high-traffic roads in largest cities, with high pollution index $[4,11,14-20]$.

On the other hand, few investigations deal with systems that replicate the conditions of pollutants produced on roads, which examine the direct impacts of vehicle engines on plants, and analyze separately the effects of responsible pollutants $[3,17,21,21,22]$. It has found that in nature the harmful effects may vary depending on the type of pollutants and the adaptation of the species to the polluted environment [3]. Different spectroscopic techniques, such as Raman, IR radiometry, thermal lens spectrometry and photoacoustic spectroscopy (PAS), have been used to obtain characteristic spectra in homogeneous and non-homogeneous materials [23]. Among these techniques, the photoacoustic spectroscopy stands out for its advantage over other spectroscopic techniques since in PAS most of the samples do not require a previous treatment, with chemical reactive, to be analyzed. Due to this advantage, PAS has allowed the characterization of different solid materials, powders, liquids, gases, biological samples and medical [24] and recently it has become a valuable tool in food science $[25,26]$.

PAS has been used to evaluate a wide variety of seeds, grains and seedlings providing valuable information on their physical properties [27-30]. Also PAS technique allows a nondestructive analysis from the optical absorption spectra of different samples, including optically opaque samples [31, 32]. PAS has allowed to obtain the optical absorption spectra of many types of solid or semisolid samples including crystalline materials, powders, amorphous, gel, etc. In the present investigation, the effect of the polluting gases $\left(\mathrm{CO}\right.$ and $\left.\mathrm{CO}_{2}\right)$, emitted by a vehicle engine, on seeds of different crops, was evaluated. Studied seeds were treated before sowing, with the aim of analyzing the optical absorption spectra of their seedlings, in a wavelength range from 250 to $750 \mathrm{~nm}$, and the physiological quality in the germination process.

\section{Materials and methods}

\subsection{Biological material}

In the present study, the used maize seeds (Zea mays L.) were grown during the spring-summer 2017 agricultural cycle, while the commercial lentil (Lens culinaris) and beans (Phaseolus vulgaris $\mathrm{L}$.) were grown during the spring-summer 2018 agricultural cycle in the State of Mexico, Mexico. All seeds were selected and classified according to their weight, size and color.

SN Applied Sciences

\subsection{Gas exposure system}

For the exposure of samples to the polluting gases, a system was designed to contain these gases, which consists of a hermetically sealed container, $102 \mathrm{~L}$ capacity with dimensions $78 \mathrm{~cm} \times 52 \mathrm{~cm} \times 36 \mathrm{~cm}$. Two mobile PVC grids were placed at the container ends, one grid in the left side, used for the entry of the polluting gases emitted by a vehicle engine with the following characteristics: 2003 model, 6 cylinders, gasoline engine without catalysts, high mileage lubricant type, recorded traveled distance: $170,000 \mathrm{~km}$ and the vehicle's exhaust is connected to a $100 \mathrm{~cm}$ long pipe so as not to expose the gas-containing system as well as the vehicle's engine to high pressures and temperatures. The right side of the container, with the other grid, is the gases outlet, considered so that the gas flows and does not saturate or causes high pressure within the system (Fig. 1). Also, a portable CO sensor (model: GCO-2008) was placed in the outlet grid, as an additional record to the internal sensors of the gas container system, to compare the data of both records.

For the automated measurement recording system, a program was designed in the Arduino free license software and its circuit was built with the integration of the sensors in real time. The used sensor models were: DHT11 (temperature and humidity), MG-811 ( $\left.\mathrm{CO}_{2}\right)$ and MQ-9 (CO), compatible with the microcontroller (Mega Arduino model) and connected to a computer for data recording. The circuit was placed inside the container, at the front (without obstructing the Petri dishes with the seed samples).

\subsubsection{Pre-treatment exposure in vehicle exhaust system}

The experiment was done with the experimental design of randomized complete blocks, with six repetitions for corn and bean seeds and four repetitions for lentil seeds, and the experimental unit for each repetition was 20,20 and 40 seeds, respectively; the seeds were homogenized by size and subsequently placed inside of sterilized Petri dishes, $9 \mathrm{~cm}$ in diameter and $1.5 \mathrm{~cm}$ deep. Petri dishes without cover were distributed within the container with polluting gas, according to the experimental design.

The exposure times were $20,40,60$ and $80 \mathrm{~min}$ for the different treatments applied to the seeds placed inside of the polluted gases container, emitted by the vehicle's engine. To maintain the $\mathrm{CO}$ and $\mathrm{CO}_{2}$ levels at 2000 ppm, without reducing and not saturating the container with gases, the following procedure was performed: the engine remained on during $5 \mathrm{~min}$, after this time the engine was off, because the cold start causes greater gas production due to the start driving cycle [9]. 


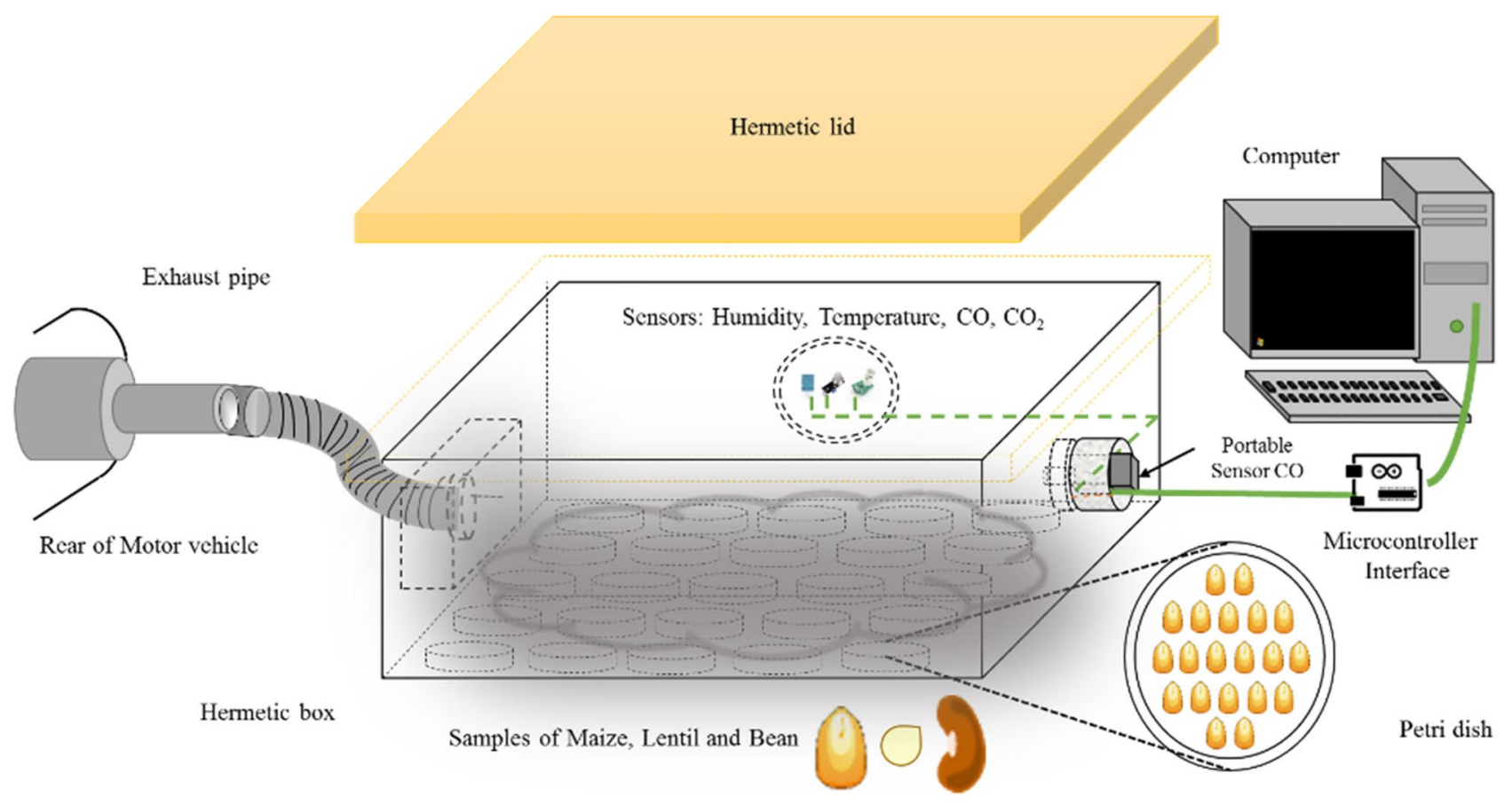

Fig. 1 Exhaust gas collection system

\subsubsection{Germination}

The pre-treated seeds were placed on filter paper inside sterilized Petri dish ( $9 \mathrm{~cm}$ in diameter and $1.5 \mathrm{~cm}$ deep) for the germination process. The established control was carried out without treatment of polluting gases. Petri dishes were placed according to the experimental design in boxes with white LED lighting programmed for an exposure time of $10 \mathrm{~h}$ per day, during the period of 10,6 and 12 days for maize, lentil and bean, respectively. Irrigation was constant every third day in the morning, with a $5 \mathrm{ml}$ supply of distilled water for each treatment. Germination was monitored daily and calculated the germination percentage (the germination percentage of the treatments was calculated considering the total number of normal seedlings among the total seeds, and the emergency rate index is calculated by daily counts of the number of seedlings emerged per day between the number of days after the seeds have been sown). At the end of the test, fresh and dry seedling weights (FW and DW) were measured. DW was obtained prior to washing and drying them, washed with distilled water and sodium hypochlorite ( $10 \mathrm{ml}$ per treatment), in the case of removing pathogen residues in some of the seeds, then dried in the oven (model: Riossa E-51) for $12 \mathrm{~h}$, at a constant temperature of $40^{\circ} \mathrm{C}$ for $72 \mathrm{~h}$. The seedlings of each variety (maize, lentil and bean) were crushed in a mortar to obtain powders thereof and be measured by photoacoustic spectroscopy. For each measurement, the sample was removed and the PA cell cleaned using a paper towel.

\subsection{PAS experimental setup}

The PA spectra of seedling powders, of the seeds treated with $\mathrm{CO}$ and $\mathrm{CO}_{2}$, were obtained by using the PAS technique in direct configuration in a wavelength ranging from 250 to $750 \mathrm{~nm}$. Figure 2 shows the PAS experimental configuration, whose excitation source is a Xenon lamp with $700 \mathrm{~W}$ power, a monochromator at $1 \mathrm{~nm}$ step, with a resolution of $\pm 5 \mathrm{~nm}$ for sampling in wavelength. The monochromatic light beam is modulated by a mechanical chopper, at $17 \mathrm{~Hz}$ frequency; an optical fiber is used to guide the modulated light beam to the PA cell that inside contains the sample. The PA cell is hermetically sealed by using two quartz windows and silicone grease as a seal, as shown in Fig. 2. The absorbed light energy generates a modulated heating in the sample that causes periodic heat flow in the adjacent air and generates pressure fluctuations in the air contained within the PA cell. Finally, gas expansion and contraction variations give rise to acoustic waves, which are detected by means of an electret microphone connected to a lock-in amplifier to obtain the PA signal amplitude and phase; these data are acquired and recorded by using a computer. 


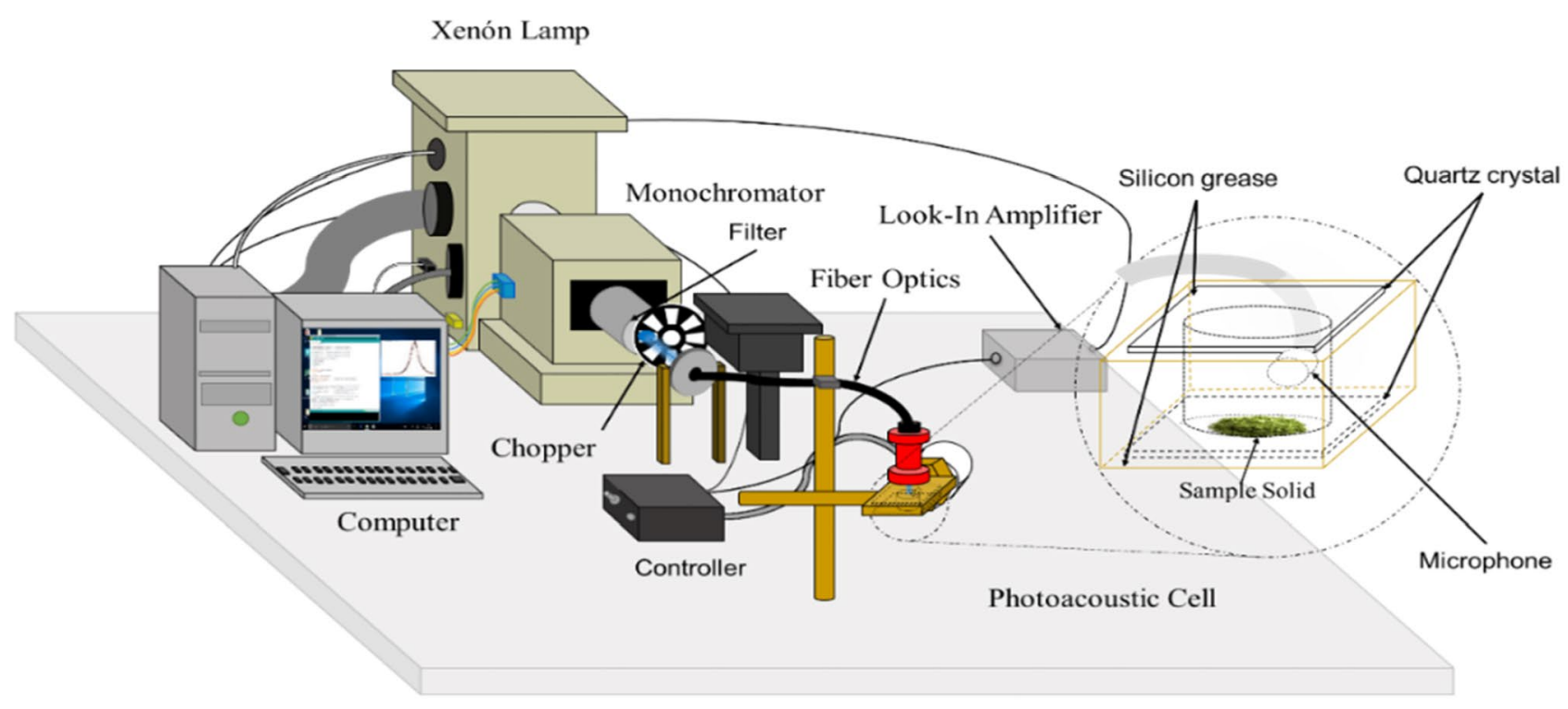

Fig. 2 PAS experimental setup

\section{Results and discussion}

Figure 3 shows optical absorption spectra of seedlings samples of maize (a), lentil (b) and bean (c) treated presowing by pollution gases at different exposure times (20, 40,60 and $80 \mathrm{~min}$ ). The spectra of these samples have different absorption bands, the first one related to flavonoids (around $295 \mathrm{~nm}$ ) [33], the second band related to carotenoids ( $400 \mathrm{~nm}-500 \mathrm{~nm}$ ) and the third one associated with chlorophyll (650 nm-700 nm) [34]. In PA spectroscopy, and also in the case of commercial UV-Vis spectroscopy, the samples are excited by a light source, where a wavelength scan is performed. For UV-Vis, the intensity of the transmitted light, through the sample, is sensed by an optical sensor which allows to obtain the optical absorption spectrum; by other hand, the absorbed light also provokes electronic transitions in molecular orbitals into the sample, these electronic excitations decay, through radiation-less transitions, and then, modulated heat is produced in the sample causing a periodic heat flow in the adjacent air and then pressure fluctuations in the air contained within the PA cell.

The PA spectra of maize seedlings samples are presented in Fig. 3a; the maximum value of the amplitude PA signal $(0.37 \mathrm{mV})$ is observed at $300 \mathrm{~nm}$ wavelength for $T_{3}$ treatment $(60 \mathrm{~min})$, and the minimum amplitude $(0.325 \mathrm{mv})$ for seedlings without treatment (control). Also it is observed that at $675 \mathrm{~nm}$ wavelength the treatment $T_{3}$ presents the maximum value of PA signal amplitude $(0.224 \mathrm{mV})$ and the minimum amplitude value $(0.149 \mathrm{mV})$ for $T_{2}$ (40 min). Thus, the amplitude level of the PA signal increased and decreased 31.76 and $14.1 \%$, respectively, when is compared with respect to the amplitude of the PA signal obtained from the seedlings without treatment (control). The PA signal of the seedlings coming from the treatments $T_{1}$ and $T_{2}$ showed a tendency of behavior similar to the control seedlings in the wavelength range of 300-525 nm. However, for the subsequent range, the level of the PA signal $(525-750 \mathrm{~nm})$ of these seedlings presented differences in the spectrum.

Figure $3 \mathrm{~b}$ shows the PA spectra of lentil seedlings samples where the control samples showed the lowest amplitude level at absorption band of $275-320 \mathrm{~nm}$, with respect to the seedlings from the other treatments applied. Note that the maximum absorption peak at $295 \mathrm{~nm}(0.55 \mathrm{mV})$ was for $T_{1}$. In the absorption band corresponding to chlorophyll (650-700 nm), the amplitude of the PA signal for seedlings control and treatment $T_{4}(80 \mathrm{~min}$ ) showed a similar behavior. The maximum absorption peak was presented by treatment $T_{2}$ (40 min), with an increase of $42.85 \%$ with respect to the amplitude of the signal from the control seedlings.

Regarding the bean seedlings (Fig. $3 c$ ), the highest amplitude of PA signal was found for treatment $T_{1}$ (20 $\mathrm{min}$ ) in the wavelength range $275-320 \mathrm{~nm}$, with an increase of $66 \%$ compared with control seedlings. The lowest amplitude of the PA signal was found for the treatment $T_{2}(40 \mathrm{~min}$ ) with a decrease of $36.36 \%$. At the peak of absorption corresponding to chlorophyll $(675 \mathrm{~nm})$, the control and $T_{4}(80 \mathrm{~min}$ ) seedlings show the highest amplitude level of PA signal. The treatments $T_{1}, T_{2}$ and $T_{3}$ had a decrease in the level of signal amplitude, with the highest decrease in $T_{1}(20 \mathrm{~min})$. In the results of the investigation, the PA spectra of the seedlings obtained by means of PAS 

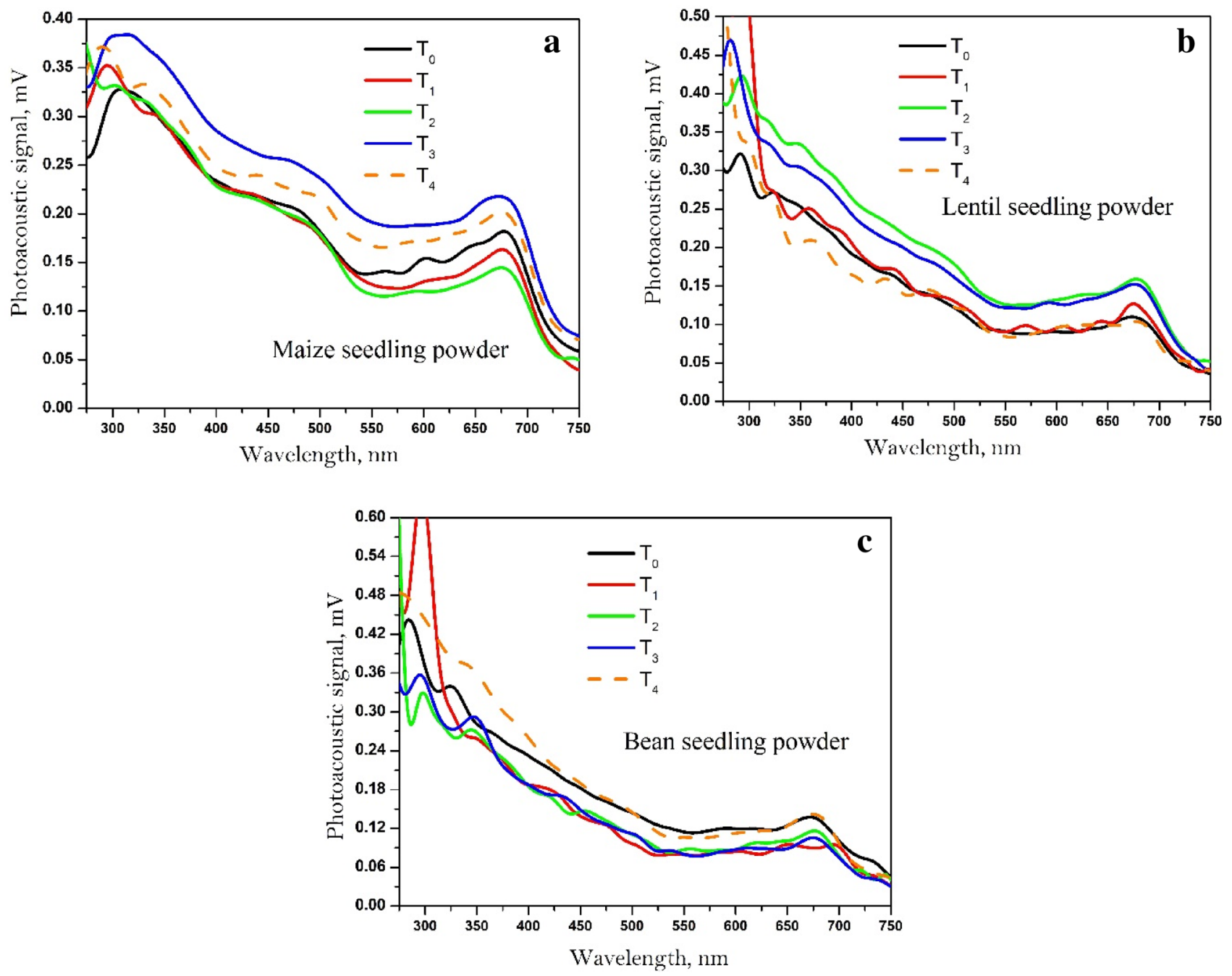

Fig. 3 Photoacoustic spectrum of seedlings of: $\mathbf{a}$ maize, $\mathbf{b}$ lentil and $\mathbf{c}$ bean treated with pollutant gases emitted from vehicle at different exposure times $(0,20,40,60$ and $80 \mathrm{~min})$

were analyzed, indicating that the level of the PA signal depends on the type of seeds, exposure time to polluting gases and the characteristics of the vehicle's engine.

In general, it is possible to say that seedlings from treated seed with $\mathrm{CO}$ and $\mathrm{CO}_{2}$ gas pollution, emitted by the vehicle engine, produce changes in the level of PA signal at the characteristic absorption peaks of flavonoids $(295 \mathrm{~nm})$ and chlorophylls $(675-700 \mathrm{~nm})$. These changes may be associated with a stimulation such as those reported by some applied physical methods [33-36] as pre-sowing treatments which tend to cause positive, negative and null stimulation effects, evidenced in the literature with the evaluation of different quality variables, such as physiology; e.g., carotenoids. The carotenoids level has been qualitatively evaluated by PAS. Some authors have reported changes in the level of PA signal in the absorption band corresponding to carotenoids, in seedlings of maize seeds, indicating increase or decrease in the level of signal amplitude according to the maize seed treatment based on applying laser light pre-sowing [37].

In this research, positive, negative and null effects were also found, according to the PA signal obtained for each treatment and seed type. Being PAS a useful technique to detected changes in seedlings due to gases pollution exposure, the PAS technique has been reported to evaluate change in bean seedlings due to the application of different concentrations of herbicides, obtaining a decrease in the PA spectrum in herbicide-treated bean leaves compared to controls. These authors indicated that the decrease in the spectrum intensity could be caused by the inhibition of photosynthetic evolution of oxygen or by a production of heat of the leaves due to the inhibition of photosynthesis by herbicides [32-34]. In this sense, the exposed seeds to polluting gases could affect their 
photosynthetic evolution, since there were changes in the PA signal level in the flavonoids peak $(295 \mathrm{~nm})$ and chlorophyll band (around $675 \mathrm{~nm}$ ) [38].

As shown in Fig. 4, there is a tendency to increase, decrease and maintain a value close to the control seedlings at the wavelength of both $295 \mathrm{~nm}$ and $675 \mathrm{~nm}$, corresponding to flavonoids and chlorophyll, respectively, depending on the seed species and the exposure times of polluting gases. Being the bean seedlings the ones that showed the greatest PA signal increase, at 20 min of exposure time, and the less affected were the maize seedlings (Fig. 4a). At $675 \mathrm{~nm}$ wavelength, the greatest increase corresponds to treated maize seedlings at $60 \mathrm{~min}$, and the largest decrease in bean seedlings treated at $20 \mathrm{~min}$ (Fig. 4b). Lentil and bean seeds show lower stimulating effect compared to maize seed, this could be due to their high flavonoid content and its defensive compounds, and it allows it to adapt to possible stress conditions [38-42]. Various research reports that high concentrations of some pollutants present in gases can be harmful to plants [17, 43]. The results obtained showed that the level of the PA signal depends on the type of sample and the exposure time to the polluting gases. Other authors have reported that the emission of polluting gases reduces productivity $[16,44]$. Also in Fig. $4 a$, b, in the error bars of the treatments, it is observed that for the wavelengths of 295 and $675 \mathrm{~nm}$ that were compared; it can be seen that the sampling error increases when the PA signal has a higher intensity and a minimum error when the PA signal strength is lower.

Table 1 shows the physiological results obtained during the corn, lentil and bean seeds germination, when exposed pre-sowing to polluting gases at different times $0,20,40,60$ and $80 \mathrm{~min}$. Statistically significant differences

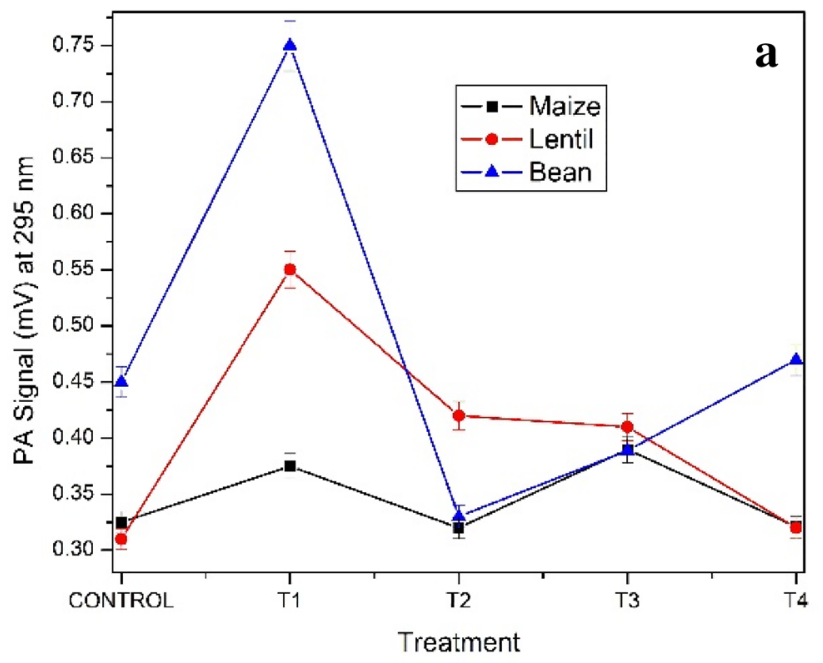

were found in germination percentage (GP), emergency velocity (EV), fresh weight (FW) and dry weight (DW) in the case of maize seed; in this seed, the GP parameter had significant statistical differences on days 2, 4 and 6. There was a seed stimulation by the treatment with polluting gases on the corn seeds. There was a highest increase in germination percentage in treatment $T_{4}$, increasing with respect to the control, $48 \%, 8 \%$ and $4 \%$, at 2,4 and 6 days, respectively. The stimulation of GP was higher on the second day of sowing established. At 2, 4 and 6 days, the emergency velocity increased by $18 \%, 16 \%$ and $12 \%$, respectively. On the contrary, the measured fresh and dry weights decreased with the increase in the applied treatment time, the maximum decrease was for treatment $T_{4}$, with a decrease of $6 \%$ and $7 \%$, for FW and DW, respectively, when compared with the control sample $\left(T_{0}\right)$.

In the case of the lentil and bean seed, there were no significant statistical differences in the evaluated variables (GP, EV, FW and DW), but there was a behavioral trend. In the case of bean seeds on days 2 and 4 , there was a tendency to increase the germination percentage, but at days 3 and 4, it tended to decrease. Similar results were found for emergency velocity. But in the case of fresh and dry weight, a slight tendency to increase was found, when comparing $T_{4}$ with control sample $\left(T_{0}\right)$, increasing $6 \%$ and $10 \%$ the FW and DW parameters, respectively. In the case of lentil seed, on days 3, 4, 5 and 6 , both for the germination percentage and emergency velocity showed a tendency to increase (between 6 and 9\%), and fresh and dry weights parameters showed a behavior tending to increase $5 \%$ and $4 \%$, respectively.

The behavior of GP is shown in Fig. 5, column (a1), (b1) and ( $\mathrm{c} 1$ ) for maize, lentil and bean seeds, respectively. The GP value for maize seeds Fig. 5a1, within the period

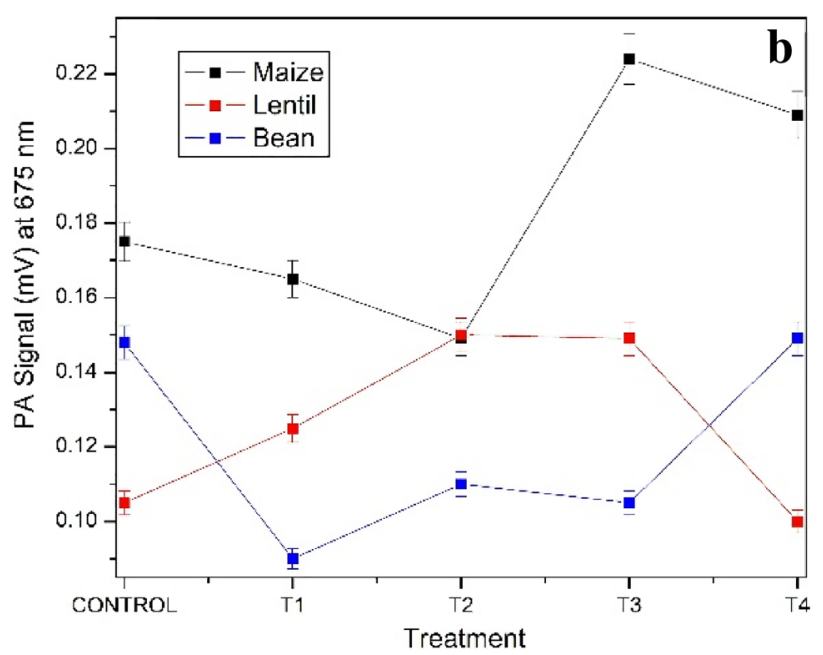

Fig. 4 Photoacoustic signal of maize, lentil and bean seedlings samples at a $295 \mathrm{~nm}$ and b $675 \mathrm{~nm}$ 
Table 1 Comparison of average values of germination variables of treated seeds at different exposition times to pollution gases

\begin{tabular}{|c|c|c|c|c|c|c|c|c|c|c|c|c|c|}
\hline Days & & 2 & 3 & 4 & 5 & 6 & 2 & 3 & 4 & 5 & 6 & 12 & 12 \\
\hline$T(\min )$ & & GP2 & GP3 & GP4 & GP5 & GP6 & EV2 & EV3 & EV4 & EV5 & EV6 & FW (gr) & DW (gr) \\
\hline \multicolumn{14}{|l|}{ Maize } \\
\hline $\mathrm{T}_{0}$ & 0 & 27.5 & 50 & 73.3 & 82.5 & 85 & 2.75 & 6.08 & 9.75 & 13.05 & 15.9 & 16 & 8.19 \\
\hline $\mathrm{T}_{1}$ & 20 & 26.7 & 50 & 70.8 & 80.8 & 80.8 & 2.66 & 6 & 9.54 & 12.77 & 15.5 & 15.63 & 8.08 \\
\hline $\mathrm{T}_{2}$ & 40 & 34.2 & 55 & 77.5 & 85.8 & 87.5 & 3.41 & 7.08 & 11 & 14.39 & 17.3 & 14.47 & 7.24 \\
\hline$T_{3}$ & 60 & 34.2 & 50 & 79.2 & 88.3 & 89.2 & 3.41 & 6.75 & 10.7 & 14.24 & 17.2 & 14.58 & 7.29 \\
\hline $\mathrm{T}_{4}$ & 80 & 40.8 & 50.8 & 79.2 & 88.3 & 89.2 & 4.08 & 7.47 & 11.4 & 14.96 & 17.9 & 14.75 & 7.31 \\
\hline LSD & & 8.67 & 5.75 & 5.98 & 6.26 & 5.85 & 0.86 & 1.02 & 1.13 & 1.26 & 1.37 & 0.6 & 0.24 \\
\hline Mean & & 32.7 & 51.2 & 76 & 85.2 & 86.3 & 3.26 & 6.67 & 10.5 & 13.88 & 16.8 & 15.08 & 7.62 \\
\hline$S$ & & $0.017^{*}$ & 0.32 & $0.02^{*}$ & 0.06 & $0.03^{*}$ & $0.01 *$ & $0.03^{*}$ & $0.01^{*}$ & $0.0074^{*}$ & $0.005^{*}$ & $0.0001^{* *}$ & $0.0001^{* *}$ \\
\hline V.C & & 22 & 9.33 & 6.53 & 6.11 & 5.63 & 22 & 12.8 & 8.96 & 7.55 & 6.79 & 3.35 & 2.71 \\
\hline $\mathrm{R}^{2}$ & & 0.56 & 0.55 & 0.63 & 0.6 & 0.64 & 0.56 & 0.6 & 0.6 & 0.62 & 0.62 & 0.73 & 0.86 \\
\hline \multicolumn{14}{|l|}{ Lentil } \\
\hline $\mathrm{T}_{0}$ & 0 & 48.5 & 74 & 88 & 90 & 90 & 12.1 & 24.5 & 35.5 & 44.45 & 52 & 4.73 & 2.32 \\
\hline $\mathrm{T}_{1}$ & 20 & 43.5 & 76.5 & 92 & 94 & 94 & 10.9 & 23.6 & 35.1 & 44.52 & 52.4 & 4.8575 & 2.31 \\
\hline $\mathrm{T}_{2}$ & 40 & 50 & 84.5 & 94.5 & 96.5 & 96.5 & 12.5 & 26.6 & 38.4 & 45.73 & 56.1 & 4.78 & 2.34 \\
\hline$T_{3}$ & 60 & 46 & 78 & 93.5 & 95.5 & 95.5 & 11.5 & 24.5 & 36.2 & 46.85 & 53.7 & 4.82 & 2.37 \\
\hline $\mathrm{T}_{4}$ & 80 & 48 & 81 & 94 & 96 & 96 & 12 & 25.5 & 37.3 & 46.85 & 54.9 & 5.01 & 2.43 \\
\hline LSD & & 15.7 & 11.2 & 7.8 & 7.89 & 7.89 & 3.93 & 5.44 & 5.71 & 6.04 & 6.38 & 0.28 & 0.08 \\
\hline Mean & & 47.2 & 78.8 & 92.4 & 94.4 & 94.4 & 11.8 & 24.3 & 36.5 & 45.92 & 53.8 & 4.84 & 2.35 \\
\hline$S$ & & 0.9 & 0.33 & 0.41 & 0.41 & 0.41 & 0.9 & 0.79 & 0.71 & 0.65 & 0.61 & 0.32 & 0.05 \\
\hline V.C & & 21.7 & 9.21 & 5.54 & 5.42 & 5.42 & 21.7 & 14.2 & 10.2 & 8.54 & 7.69 & 3.79 & 2.41 \\
\hline $\mathrm{R}^{2}$ & & 0.4 & 0.48 & 0.32 & 0.32 & 0.32 & 0.4 & 0.42 & 0.44 & 0.45 & 0.45 & 0.73 & 0.53 \\
\hline \multicolumn{14}{|l|}{ Bean } \\
\hline $\mathrm{T}_{0}$ & 0 & 7.5 & 17.5 & 35.8 & 55.8 & 77.5 & 0.75 & 1.91 & 3.7 & 5.94 & 8.52 & 21.61 & 6.58 \\
\hline $\mathrm{T}_{1}$ & 20 & 9.16 & 19.2 & 20 & 40 & 78.3 & 0.91 & 2.19 & 3.19 & 4.79 & 7.4 & 20.98 & 6.84 \\
\hline$T_{2}$ & 40 & 10.8 & 20.8 & 21.7 & 41.7 & 77.5 & 1.08 & 2.47 & 3.55 & 5.22 & 7.8 & 22.04 & 7.43 \\
\hline $\mathrm{T}_{3}$ & 60 & 10 & 20 & 20.8 & 40.8 & 79.2 & 1 & 2.33 & 3.37 & 5 & 7.64 & 21.15 & 7.05 \\
\hline $\mathrm{T}_{4}$ & 80 & 12.5 & 22.5 & 22.5 & 42.5 & 82.5 & 1.25 & 2.75 & 3.87 & 5.57 & 8.32 & 22.4 & 7.25 \\
\hline LSD & & 3.57 & 3.57 & 9.3 & 9.3 & 5.4 & 0.35 & 0.59 & 0.84 & 1.14 & 1.27 & 1.59 & 0.63 \\
\hline Mean & & 10 & 20 & 24.2 & 44.2 & 79 & 1 & 2.33 & 3.54 & 5.3 & 7.94 & 21.63 & 7.03 \\
\hline$S$ & & 0.08 & 0.08 & 0.01 & 0.01 & 0.31 & 0.08 & 0.08 & 0.49 & 0.27 & 0.35 & 0.34 & 0.08 \\
\hline V.C & & 29.7 & 14.9 & 32.2 & 17.6 & 5.7 & 29.7 & 21.2 & 19.8 & 17.96 & 13.4 & 6.13 & 7.51 \\
\hline $\mathrm{R}^{2}$ & & 0.6 & 0.6 & 0.56 & 0.56 & 0.58 & 0.6 & 0.6 & 0.27 & 0.26 & 0.26 & 0.45 & 0.53 \\
\hline
\end{tabular}

$T$ seed exposure time to contaminants, GP germination percentage, EV emergency velocity, FW fresh weight, DW dry weight, $L S D$ low significant difference, $V C$ variation coefficient, $R^{2}$ determination coefficient, $S$ significance ${ }^{* * * *}$ )

of 5-6 days, the $T_{1}$ treatment ( $20 \mathrm{~min}$ ) was lower than the seed without exposure to polluting gases (control), while in others, treatments GP had better performance. Figure $5 \mathrm{~b} 1$ shows the GP value of the lentil seeds, where it is observed that from the third day of germination, all treatments show an improvement when compared to the control. At the end of the germination process, the $T_{2}$ treatment shows the best GP value and the lowest value for control.

In Fig. 5c1, the bean seed treatments show that during the period of 3-6 days it was observed lower GP values for seeds exposed to the polluting gases, when compared to the control sample, while at the sixth day, the treatments show an improvement in their GP behavior compared to the control. At the end of the germination process, the $T_{4}$ treatment has the highest GP value. Figure $5 \mathrm{a} 2$ shows that the treatment $T_{4}(80 \mathrm{~min}$ ) has the best EV performance compared to the control and $T_{1}$ shows the worst performance. For lentil seeds, all the treatments show better EV performance than the control (Fig. 5b2), whereas for bean seed, the $T_{4}$ treatment shows the best EV performance compared with the other treatments and control (Fig. 5c2).

Fresh weight (FW) and dry weight (DW) values of germinated maize seeds are shown in Fig. 5a3, which show 



Fig. 5 Physiological quality parameters of maize (a), lentil (b) and bean (c) at different pollutant exposure times (0, 20, 40, 60 and 80 min): (a1), (b1), (c1) germination percentage, (a2), (b2), (c2) emergency speed and (a3), (b3), (c3) fresh and dry weight

a trend in their behavior, highlighting that the control sample (without exposure of contaminating gases) shows higher FW and DW values than the seeds exposed to contaminants. On the other hand, the $T_{2}$ treatment (40 min) has the lowest FW and DW values. For the lentil seeds (Fig. 5b3), it is observed that the lowest FW and DW values correspond to the control and $T_{2}$ treatments, respectively, while $T_{4}$ has the best performance for both. For the bean seeds (Fig. $5 \mathrm{c} 3$ ),$T_{2}$ has the highest DW value and the control has the lowest; finally, in the FW measurements, the $T_{4}$ treatment has the highest value and $T_{2}$ the lowest value.

Another important factor observed during the germination process is that at a longer exposure time no fungi were found during the germination of maize and bean seedlings compared to the control where some seeds were infected. The effects of exhaust emissions from motor vehicles on the seed germination process vary according to the degree and time of exposure to the pollution gases and the seed type. The wide distribution of flavonoids in lentil and bean seeds suggests their fundamental importance and prophylactically protection of the seedlings against pathogens [45].

The changes observed in the seed germinating could be due to the tolerance of each specie to pollutants that are absorbed by the different treatments and the accumulation of other pollutants from the engine exhaust of the used vehicle: e.g., hydrocarbons, lead, metal powder, soot particles, etc., that have to be considered an important additional factor responsible in the process of seed germination and seedling growth $[17,18,44]$.

High concentrations of $\mathrm{CO}_{2}$, compared with the literature reports, have allowed to detect how it influences the physiological functions of the development of crops and seeds, it has been found that it reduces the germination of some rice seeds, the production of abnormal seedlings and the appearance of dead seeds are indicators of a 
physiological deterioration presented in the seed, strongly indicating that a high level of $\mathrm{CO}_{2}$ induced irreversible damage to the quality of the seed. $\mathrm{CO}_{2}$ exposure at levels of $720 \mathrm{ppm}$ reduces germination of the produced seed, while exposure to 610 and 720 ppm reduces seed vigor [46]. In the case of some legumes such as chickpea seeds, some authors suggest that the increase in atmospheric $\mathrm{CO}_{2}$ could have an adverse impact on viability, germination and cause a nutritional imbalance [47]; in the case of beans, it has been reported that by increasing $\mathrm{CO}_{2}$ concentration indices do not influence the seed composition, the emergence or vigor of the produced seedlings [48].

Another important factor, together with the polluting gases that affect the seed germination process, is the temperature [49], in the present research, the average temperature, during the exposure to the polluting gases, increased $\sim 3^{\circ} \mathrm{C}$ from initial temperature $\left(27^{\circ} \mathrm{C}\right)$, and this increment in the air temperature is associated with the increase in $\mathrm{CO}_{2}, \mathrm{CO}$ and other polluting gases that could have substantially influence on the seed development and thus reducing their quality. This research shows that the results were stimulating and inhibitory depending on the seed and treatment.

\section{Conclusions}

The photoacoustic spectroscopy (PAS) technique is a useful tool that provides reliable information on optical properties in natural pigments of biological samples (seedling powder) such as carotenoids (with optical absorption band ranging from 400 to $500 \mathrm{~nm}$ ) in the case of maize, flavonoids (with an optical absorption peak around $295 \mathrm{~nm}$ ) and chlorophylls (with optical absorption band ranging from 650 to $700 \mathrm{~nm}$ ). The characterized samples (seedling powders) were obtained from the germinated seeds, with previous treatment of different exposure times of polluting gases. The greatest changes in absorption spectra were obtained with respect to the control seed (without gas exposure), and the lentil seed has the lowest signal values in its optical absorption spectrum.

The physiological parameters during seed germination show a similar behavior shown in PAS. The effects of pollutants varied depending on the seed treatment, finding that the most sensitive seed, exposed to polluting gases, is the maize seed and the least affected was the lentil seed. Changes in GP and EV showed a tendency to improve in the most treatments exposed to polluting gases. The FW and DW measurements found the poor viability of the seeds exposed to pollutants finding a decrease in maize and differences that varied with the several exposure times for lentil bean seeds. In the case of maize and bean seeds, less pathogen infection was found for the longer exposure time treatment $\left(T_{4}=80 \mathrm{~min}\right)$ compared to the control of both seeds; finally, in the case of lentil seed, these effects were not observed.

Acknowledgements The authors would like to thank the Instituto Politecnico Nacional, through the CONACYT, COFAA, EDI and projects SIP scholarships. The support Research and Postgraduate Secretariat (Project SIP 20195955), Joel Eduardo Valencia Hernandez thank for the support, for Ph.D. studies, through the grant awarded by Conacyt and also, Photothermal Techniques Laboratory of Physics Department, CINVESTAV-IPN for the support to develop the experiments of the present study. We also thank Ing. Esther Ayala for her technical support at the Physics Department, CINVESTAV-IPN.

\section{Compliance with ethical standards}

Conflict of interest On behalf of all authors, the corresponding author states that there is no conflict of interest.

\section{References}

1. WHO (2018) First WHO Global conference on air pollution and health. improving air quality, combatting climate change-saving lives, Geneva, Switzerland. https://www.who.int/airpolluti on/events/conference/en/

2. Kleeman MJ, Riddle SG, Robert MA, Jakober CA (2008) Lubricating oil and fuel contributions to particulate matter emissions from light-duty gasoline and heavy-duty diesel vehicles. Environ Sci Technol 1:235-242

3. Ashenden $\mathrm{T}$, Ashmore $\mathrm{M}$, Bell JNB, Bignal K, Binnie J, Cape J, Caporn S, Carroll J, Davison A, Hadfield P, Honour S, Lawton K, Moore S, Power S, Shields C (2003) Impacts of vehicle emissions on vegetation, Urban Transport and the Environment in the 21st Century, 64:313-322

4. Bell J, Honour S, Power S (2011) Effects of vehicle exhaust emissions on urban wild plant species. Environ Pollut 159:1984-1990

5. Wright J (2002) Chronic and occult carbon monoxide poisoning: we don't know what we're missing. Emerg Med J 19:386-390

6. Chamberlain O (2016) Carbon-monoxide (CO): a poisonous gas emitted from automobiles, its effect on human health. Adv Automob Eng 5:1-7

7. Calderón-Garcidueñas L, Zzzarelli B, Acuna H, Garcia R, Gambling TM, Osnaya N, Monroy S, Tizapantzi MDR, Carson JL, Villarreal-Calderon A, Rewcastle B (2002) Air pollution and brain damage. Toxicol Pathol 30:373-389

8. Dey S, Dhal GC (2019) Materials progress in the control of $\mathrm{CO}$ and $\mathrm{CO}_{2}$ emission at ambient conditions: an Overview. Mater Sci Energy Techno 2:607-623. https://doi.org/10.1016/j. mset.2019.06.004

9. Yung-Chen Y, Jiun-Horng T, Hui-Fen Y, Hung-Lung C (2009) Comparison of exhaust emissions resulting from cold-and hot-start motorcycle driving modes. J Air Waste Manag Assoc 59:1339-1346

10. Calderón-Garcidueñas $L$, Maronpot RR, Torres-Jardon $R$, Henríquez-Roldan C, Schoonhoven R, Acuna-Ayala H, Villarreal- Calderon A, Nakamura J, Fernando R, Reed W, Azzarelli B, Swenberg JA (2003) DNA damage in nasal and brain tissues of canines exposed to air pollutants is associated with evidence of chronic brain inflammation and neurodegeneration. Toxicol Pathol 31:524-538

11. Fonken L, Xu X, Weil Z, Chen G, Sun Q, Rajagopalan S, Nelson R (2017) Air pollution impairs cognition, provokes depressive-like 
behaviors and alters hippocampal cytokine expression and morphology. Molecular Psychiatry 16:987-995

12. Rasheed I, Zafar Iqbal M, Shafiq M, Athar M (2017) Effects of automobile pollution on the phenology of some street plants. Sci Agric 19:39-46

13. Brust GE (2007) Air pollution effects on vegetables. Universidad de Maryland, Maryland

14. Wittenberghe SV, Alonso L, Verrelst J, Hermans I, Delegido J, Veroustraete F, Valcke R, Moreno J, Samson R (2013) Upward and downward solar-induced chlorophyll fluorescence yield indices of four tree species as indicators of traffic pollution in Valencia. Environ Pollut 173:29-37

15. Iqbal M, Shafig M, Zaidi SQ, Athar M (2015) Effect of automobile pollution on chlorophyll content of roadside urban trees. Glob J Environ Sci Manag 1:283-296

16. Ganatsas $P$, Tsakaldimi $M$, Zachariadis $G$ (2011) Effect of air traffic pollution on seed quality characteristics of Pinus brutia. Environ Exp Bot 74:157-161

17. Shafiq M, Zafar lqbal M (2007) Germination and seedling behaviours of seeds of peltophorum pterocarpum D.C.Baker Ex K.Heyne growing under motor vehicle emission. Turk J Bot 31:565-570

18. Shafiq M, Zafar lqbal M (2012) Effect of autoexhaust emission on germination and seedling growth of an important arid tree Cassia siamea Lamk. Emir J Food Agric 24:234-242

19. Honour SL, Bell JNB, Ashenden TW, Cape JN, Power SA (2009) Responses of herbaceous plants to urban air pollution: effects on growth, phenology and leaf surface characteristics. Environ Pollut 157:1279-1286

20. Sharma N, Singh M, Bhardwaj SK (2018) Effect of auto-exhaust emissions on seed germination of tree species growing along roadside in industrial area of himachal pradesh, india. Int J Econ Plants 5:071-075

21. Zafar N, Athar M, Zafar M, Shafiq M (2016) Effect of diesel generator exhaust pollutants on growth of Vinca rosea and Ruellia tuberosa. J Appl Sci Environ Manag 20:1191-1197

22. Rai A, Kulshreshtha K, Srivastava PK, Mohanty CS (2010) Leaf surface structure alterations due to particulate pollution in some common plants. Environmentalist 30:18-23

23. Mondal NK, Panja D, Das C, Dey U, Das K (2014) Impacts of vehicle exhaust black soot on germination of gram seed (Cicer arietinum L.). Commun Plant Sci 4:1-9

24. Bialkowski SE (1996) Chemical analysis: a series of monographs on analytical chemistry and its applications. J.D. Winefordner, Logan UT, p 584

25. Sigrist MW (1999) Photoacoustic spectroscopy, method and instrumentation. In: Encyclopedia of spectroscopy and spectrometry, vol 3, p 1810

26. Eloy Dias RC, Valderrama P, Marco PH, Dos Santos Scholz MB, Edelmann M, Yeretzian C (2018) Quantitative assessment of specific defects in roasted ground coffee via infrared-photoacoustic spectroscopy. Food Chem 255:132-138

27. Luterotti S, Bicanic D, Kljak K, Grbesa D, Martínez SME, Spruijt R (2011) Assaying total carotenoids in flours of corn and sweetpotato by laser photoacoustic spectroscopy. Food Biophys 6(12):19

28. Marquezini MV, Cella N, Mansanares AM, Vargas H, Miranda LCM (1991) Open photoacoustic cell spectroscopy. Meas Sci Technol 2:396-401

29. Gordillo Delgado F, Zárate Rincón F, Mejía Morales C (2012) Comparison between conventional and organic rice using photoacoustic technique. Dyna 79:7-13

30. Hernández-Aguilar C, Domínguez-Pacheco A, Cruz-Orea A, Ivanov R (2019) Photoacoustic spectroscopy in the optical characterization of foodstuff: a review. J Spectrosc. https://doi. org/10.1155/2019/5920948

31. Rico Molina R, Hernández-Aguilar C, Dominguez-Pacheco A, Cruz-Orea A, Canseco MA (2013) Alternative method to

SN Applied Sciences characterize corn grain by means of photoacoustic spectroscopy. Int J Thermophys 34:1540-1548

32. Michaelian KH (2010) Photoacoustic IR spectroscopy: instrumentation, applications and data analysis. Wiley

33. Kinney JB, Staley RH (1982) Applications of photoacoustic spectroscopy. Annu Rev Mater Sci 12:295-321

34. Domínguez-Pacheco A, Hernández-Aguilar C, Cruz-Orea A (2017) Photoacoustic determination of non-radiative relaxation time of absorbing centers in maize seeds. Int J Thermophys $38: 7-8$

35. Szigeti Z, Nagel EM, Buschmann C, Lichtenthaler HK (1989) In vivo photoacoustic spectra of herbicide-treated bean leaves. J Plant Physiol 134:104-109

36. Araújo SS, Paparella S, Dondi D, Bentivoglio A, Carbonera D, Balestrazzi A (2016) Physical methods for seed invigoration: advantages and challenges in seed technology. Front Plant Sci $7: 1-12$

37. Pietruszewski S, Martínez E (2015) Magnetic field as a method of improving the quality of sowing material: a review. Int Agrophys 29:377-389

38. Hernandez-Aguilar C, Dominguez-Pacheco A, Carballo AC, CruzOrea A, Ivanov R (2008) The carotenoid content in seedlings of maize seeds irradiated by a $650 \mathrm{~nm}$ diode laser: qualitative photoacoustic study. Eur Phys J Special Topics 153:515-518

39. Aguilar CH, Pacheco FAD, Orea AC, Tsonchev RI (2015) Thermal effects of laser irradiation on maize seeds. Int Agrophysics 29:147-156

40. Aoki T, Akashi T, Ayabe SI (2000) Flavonoids of leguminous plants: structure, biological activity, and biosynthesis. Int J Plant Res 113:475-488

41. Aquino-Bolaños EN, García-Díaz YD, Chavez-Servia JL, CarrilloRodríguez JC, Vera-Guzmán AM, Heredia-García E (2016) Anthocyanin, polyphenol, and flavonoid contents. Emir J Food Agr 28:581-588

42. Samanta A, Das G, Das SK (2011) Roles of flavonoids in plants. Int J Pharm Sci Tech 6:12-35

43. Panche AN, Diwan AD, Chandra SR (2016) Flavonoids: an overview. J Nutr Sci 5:1-15

44. Grantz D, Garner J, Johnson D (2003) Ecological effects of particulate matter. Environment 29:213-219

45. Shafiq $M$, lqbal MZ, Athar M, Qayyum M (2009) Effect of auto exhaust emission on the phenology of Cassiasiamea and Peltophorumpterocarpum growing in different areas of Karachi. Afr J Biotechnol 8:2469-2475

46. Kubasek WL, Shirley BW, McKillop A, Goodman HM, Briggs W, Ausubel FM (1992) Regulation of flavonoid biosynthetic genes in germinating arabidopsis seedlings. The Plant Cel 4:1229-1236

47. Lamichaney A, Swain DK, Biswal P, Kumar V, Singh NP, Hazra KK (2019) Elevated atmospheric carbon-dioxide affects seed vigour of rice (Oryza sativa L.). Environ Exp Bot 157:171-176

48. Saha S, Chakraborty D, Sehgal VK, Pal M (2015) Rising atmospheric $\mathrm{CO} 2$ : potential impacts on chickpea seed quality. Agric Ecosyst Environ 203:140-146

49. Thomas JMG, Prasad PVV, Boote KJ, Allen LH Jr (2009) Seed composition, seedling emergence and early seedling vigour of red kidney bean seed produced at elevated temperature and carbon dioxide. J Agron Crop Sci 195:148-156

50. Hampton J, Boelt B, Rolston M, Chastain T (2013) Effects of elevated $\mathrm{CO} 2$ and temperature on seed quality. J Agric Sci 151:154-162

Publisher's Note Springer Nature remains neutral with regard to jurisdictional claims in published maps and institutional affiliations. 